\title{
Mixed Failure to Thrive
}

National Cancer Institute

\section{Source}

National Cancer Institute. Mixed Failure to Thrive. NCI Thesaurus. Code C128741.

Failure to thrive due to both organic and non-org anic causes. 